\title{
Behaviour change strategies to influence antibiotic prescribing in acute care: a systematic review
}

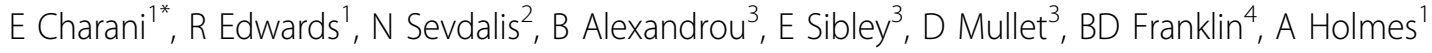 \\ From International Conference on Prevention \& Infection Control (ICPIC 2011) \\ Geneva, Switzerland. 29 June - 2 July 2011
}

\section{Introduction / objectives}

Antibiotic usage in acute care is widely reported to be suboptimal. Inappropriate use of antibiotics is a major contributing factor to emergence of multi-drug resistance and healthcare associated infection. Addressing antibiotic prescribing behaviour (APB) is a key component of antibiotic stewardship.

\section{Methods}

We carried out a novel systematic review of both qualitative and quantitative literature on APB in acute care. We assessed the extent to which behavioural sciences and social marketing were applied and whether this could be related to the effectiveness of reported outcomes. MEDLINE, EMBASE, ASSIA, Business Source Complete, The Cochrane Library, PsycINFO, Dare and HMIC were searched for studies undertaken in 19992009 and published in English.

\section{Results}

5 qualitative and 5 quantitative studies out of a total of 180 met the quality criteria. Qualitative studies highlight the predominant influence of social norms, attitudes, and beliefs on APB. Quantitative studies reporting interventions to optimise antibiotic prescribing do not use theoretical science or primary research to inform the design and choice of the interventions deployed.

\section{Conclusion}

Despite qualitative evidence demonstrating the impact of behavioural determinants and social norms on prescribing, these influences are not given due consideration in

${ }^{1}$ Centre for Infection Prevention and Management, Imperial College London, London, UK

Full list of author information is available at the end of the article the design and evaluation of interventions. To ensure a better understanding of APBs and to improve the quality of interventions and research in this area, the application of behavioural sciences supported by appropriate multidisciplinary collaboration is recommended.

\section{Disclosure of interest}

None declared.

\section{Author details}

${ }^{1}$ Centre for Infection Prevention and Management, Imperial College London, London, UK. '2Deaprtment of Surgery and Cancer and Imperial Centre for Patient Safety and Service Quality, Imperial College London, London, UK. ${ }^{3} \mathrm{Dr}$ Foster Intelligence, London, UK. ${ }^{4}$ Centre for Medication Safety and Service Quality, Imperial College Healthcare NHS Trust, London, UK.

Published: 29 June 2011

doi:10.1186/1753-6561-5-S6-O43

Cite this article as: Charani et al:: Behaviour change strategies to

influence antibiotic prescribing in acute care: a systematic review. BMC Proceedings 2011 5(Suppl 6):O43.

Submit your next manuscript to BioMed Central and take full advantage of:

- Convenient online submission

- Thorough peer review

- No space constraints or color figure charges

- Immediate publication on acceptance

- Inclusion in PubMed, CAS, Scopus and Google Scholar

- Research which is freely available for redistribution
C Biomed Central

C 2011 Charani et al; licensee BioMed Central Ltd. This is an open access article distributed under the terms of the Creative Commons Attribution License (http://creativecommons.org/licenses/by/2.0), which permits unrestricted use, distribution, and reproduction in any medium, provided the original work is properly cited. 